\title{
Modeling of Aerobic Biodegradation and Oxygen Consumption in Benthic Sediments
}

\author{
Boris M. Dolgonosov \\ Institute of Water Problems, Russian Academy of Sciences
}

Abstract. A brief overview of the existing chemical and biological models of biodegradation in porous media is given. A revised biological model of aerobic degradation of organic matter in benthic sediments is developed. The model is based on steady-state balance equations for microbial mass, organic matter, and oxygen. The biomass balance equation involves a logistic trophic function (instead of the classical Malthusian one) describing the self-regulation of microbial abundance. One of the corollaries of the model is the dependence of the decay rate upon the organic matter content $S$ in the form $d S / d t \propto S^{2} /\left(S+K_{S}\right)^{2}$ (where $K_{S}$ is a constant) that implies two extreme cases: $d S / d t$ is independent of $S$ at small $K_{S}$ (refractory organics) and $d S / d t \propto S^{2}$ at large $K_{S}$ (labile organics), instead of the commonly used law $d S / d t \propto S$. The oxygen consumption rate $J$ is expressed through the oxygen concentration $O_{0}$ in the overlying water and three generalized parameters. This function demonstrates the effect of the plateau at large $O_{0}$. The dependence $J\left(O_{0}\right)$ is calibrated for the three experimental systems of the literature, two of which have high oxygen consumption rates and one low. For the latter, the model parameters are estimated and their correspondence to the evidence available is discussed. Depth profiles of oxygen, organic matter, and biomass are computed and the aerobic zone thickness is determined.

\section{INTRODUCTION}

The oxygen regime of benthic sediments is one of the basic factors predetermining the state of the benthic microbial community, the redox conditions, the interphase equilibria and, as a result, the sediment accumulating capacity with respect to different contaminants and the possibility of releasing the contaminants from the sediments into the overlying water. Aerobic biodegradation in benthic sediments is commonly modeled on the basis of overall chemical reactions reflecting organic matter decay with no regard to the biological mechanisms of the process. In such chemical models, it is assumed that organic matter decays with a rate proportional to its content. The validity conditions for this law are unknown. Therefore, it is of interest to consider the biological mechanisms of 
the decay. Biological models are widely used for describing biodegradation in groundwater aquifers, however these have not yet been applied to benthic sediments. These models cannot be transferred without changes from aquifers to benthic sediments because of the peculiarities of the latter such as insignificant filtration flows, immobile microbial cells attached to solid surfaces, and particulate organic matter settling onto the sediment surface. In these conditions, the microbial abundance is controlled not by cell transport as in flow-through systems (e.g. continuous fermenters conventionally described by the chemostat model [Howell, 1983]) but by the purely biological mechanism of competition between different microbial groups.

The objective of this work is to involve the biological mechanisms in modeling the aerobic degradation of organic matter in benthic sediments in order to determine the oxygen consumption rate of the sediments as a function of the overlying dissolved oxygen and process parameters.

The structure of the paper is as follows. A brief overview of the existing chemical and biological models of biodegradation in porous media (benthic sediments and groundwater aquifers) is made first. Then on this basis, a biological model is constructed subject to the peculiarities of benthic sediments. From the model equations, an expression for the oxygen flux into the sediments is deduced. This expression is applied to three experimental systems of the literature. Its calibration allows the model parameters to be estimated. The results are discussed in terms of their correspondence to the available evidence in the literature. The predicted decay rate as a function of the organic matter content is compared to the function adopted in the familiar chemical models.

\section{MODELING BIODEGRADATION IN POROUS MEDIA}

\section{Chemical Models}

The chemical models presented below do not include equations for microbial populations and are based on overall chemical reactions sketching biological transformations of organic and mineral components. The mathematical description uses the methods of formal chemical kinetics.

Park and Jaffe [1996] modeled biodegradation in benthic sediments by analyzing both aerobic and some anaerobic processes in order to find the redox potential depth profile. The aerobic biodegradation was described schematically by the overall reaction:

$$
\left(\mathrm{CH}_{2} \mathrm{O}\right)_{106}\left(\mathrm{NH}_{3}\right)_{16} \mathrm{H}_{3} \mathrm{PO}_{4}+106 \mathrm{O}_{2}=106 \mathrm{CO}_{2}+16 \mathrm{NH}_{3}+\mathrm{H}_{3} \mathrm{PO}_{4}+106 \mathrm{H}_{2} \mathrm{O} \text {. }
$$

For this organic compound, the specific oxygen consumption is $2.67 \mathrm{~g} \mathrm{O} / \mathrm{g}$ C. Anaerobic processes influence the aerobic process by generating reduced chemicals $\left(\mathrm{NH}_{3}, \mathrm{Mn}^{2+}, \mathrm{Fe}^{2+}, \mathrm{H}_{2} \mathrm{~S}\right.$, and $\left.\mathrm{CH}_{4}\right)$, which emanate into the oxic zone and consume oxygen via their oxidation. The model assumes the 
degradation rate to be proportional to the organic matter content $S$, i.e. $d S / d t=-k S$. The specific reaction rate is taken as the sum of Monod terms: $k=\Sigma k_{m i} C_{i} /\left(K_{i}+C_{i}\right)$, where $C_{i}$ is the concentration of the ith oxidizing agent $\left(\mathrm{O}_{2}, \mathrm{NO}_{3}^{-}, \mathrm{Mn}(\mathrm{IV}), \mathrm{Fe}(\mathrm{III}), \mathrm{SO}_{4}^{2-}\right), K_{i}$ is the half-saturation constant, and $k_{m i}$ is the maximum reaction rate. The proportionality law in the spirit of formal kinetics is apparently empirical and requires a system-dependent confirmation. Moreover on general grounds, the rate of biodegradation must depend on microbial abundances and the model must additionally include balance equations for each microbial population. A proper account for the microbial abundances can essentially change not only the model equations, but also the kinetics of organic matter decay and, as a consequence, the oxygen consumption rate of the sediments.

Mizandrontsev [1990] modeled the oxygen consumption of benthic sediments caused by aerobic biodegradation on the basis of balance equations for oxygen and organic matter written in the common form

$$
\frac{\partial C}{\partial t}+\frac{\partial V C}{\partial Z}=\frac{\partial}{\partial Z} D \frac{\partial C}{\partial Z}-k C
$$

( $C$ is the concentration of either oxygen or organic carbon), which involves: (i) the sediment growth rate $V$ due to the deposition of particulate matter; (ii) the effective diffusivity $D$ of oxygen or particulate organic matter in the sediment dependent on the porosity and the bioturbation intensity; and (iii) the oxygen or organic matter decay as a first order reaction with a certain specific rate $k$. To incorporate biological effects into the equation, the specific reaction rate was assumed to be proportional to the microbial abundance dependent on the sediment depth $Z$ according to a predefined (exponential) function fitting some empirical data, so that $k$ takes the form $k \propto \exp (-\alpha Z)$, where $\alpha$ is a constant. Solving equation (2) in a steady state at a given oxygen concentration $C=O_{0}$ in the overlying water yields the oxygen flux into the sediment as a linear function of $O_{0}$. Some empirical evidence indicates that this linearity occurs at any $O_{0}$ (up to saturation) in oligotrophic conditions, but only at small $O_{0}$ in mesotrophic and especially in eutrophic conditions, where this dependence levels off at large $O_{0}$ [Fillos and Molof, 1972; Belanger, 1981; Dzyuban, 1987]. To describe this effect, it is necessary to involve nonlinear mechanisms, such as oxygen-substrate-cells interactions.

Similar chemical models, representing the oxygen consumption as a first order reaction with respect to the concentration of degradable organic carbon, have also been studied in earlier works [Emerson and Bender, 1981; Emerson, 1985; Archer et al., 1989].

Cai et al. [1995] described organic carbon degradation with calcite dissolution near the sediment-water interface using a steady-state numerical model, encompassing diffusion, advection, and multiple reaction terms, applied to their own experimental data. Following Rabouille and Gaillard [1991], the oxygen consumption rate and organic matter decay rate are assumed to be a first order 
function of the organic matter content $d O / d t=-k_{1} S, d S / d t=-k_{2} S$ and depend on the oxygen concentration according to the Monod formula: $k_{1} \propto k_{2} \propto O /\left(O+K_{O}\right)$. The model does not include equations for microbial populations. Pore-water advection due to sediment compaction is assumed to be negligible compared to the effect of diffusion and reaction on the pore-water profiles of dissolved species; the same assumption was made earlier by Boudreau [1987, 1991], Archer et al. [1989], and Rabouille and Gaillard [1991]. The model involves bioturbation, responsible for mixing the top sediment with attached organic matter. Owing to this, an effective diffusion term must be available in the kinetic equation for organic matter. It was revealed that a high oxygen consumption rate observed is related to a very labile fraction of organic carbon which has a degradation rate constant of approximately $1.4 \mathrm{yr}^{-1}$. Half of the benthic oxygen flux is consumed in the top $1 \mathrm{~mm}$ of sediment. Based on this observation, the authors suggest that there may exist a very labile fraction of organic carbon within the top 1 to $2 \mathrm{~mm}$ of sediment. This very labile organic carbon fraction may have a half-life of less than 0.5 year and may be responsible for the seasonal change of the benthic oxygen flux. Cai et al. [1995] suppose that this very labile organic carbon is not mixed downward by biological mixing.

The essential problem with these chemical kinetic models is that it is not known under what conditions the empirical decay law $d S / d t \propto S$ is valid. It is perhaps more reasonable not to predefine the decay law but to incorporate in the model an additional kinetic equation for the microbial mass (and analogous equations for nutrients, if necessary), which accounts for the biological mechanisms of oxygen consumption and allows us to find what decay law results from the system of equations.

\section{Biological Models}

The biological models involve kinetic equations not only for oxygen and the substrate (as well as nutrients and other chemicals, if necessary), but also for microbial populations metabolizing organic matter and affecting the oxygen consumption. Some general models were reviewed by Howell [1983], Cunningham and Nisbet [1983], and Button [1985]. The basic model for biomass growth is $d B / d t=\mu B-k_{d} B$ with the specific growth rate commonly represented by the Monod formula $\mu=\mu_{m} S /\left(K_{S}+S\right)$ [Howell, 1983; Button, 1985], which reflects the substrate limitation on the growth (the system of notation is presented in Table 1).

Most biological models are applied to soil and aquifer systems. The existing models can be classified by the number of substrates (single- or multiple-substrate models), the number of microbial populations (single- or multiple-population models), and the spatial structure (macroscopic, microcolony, or biofilm) [Widdowson, 1991]. A macroscopic model is appropriate for systems 
where microbial cells do not form large colonies or thick films and thus the interphase mass transfer limitations may be neglected [Wood et al., 1994].

Essaid et al. [1995] developed a model with multiple substrates metabolized with several microbial populations. The total biodegradation rate is the sum of each population rate and the latter is the production of the terms $S_{i} /\left(K_{i}+S_{i}\right)$ for each (ith) limiting component of the substrate (the socalled modified Monod kinetics).

Table 1. Notation

\begin{tabular}{|c|c|c|}
\hline $\begin{array}{l}\text { Sym- } \\
\text { bol }\end{array}$ & Unit & Description \\
\hline$B$ & g cells $\mathrm{m}^{-3}$ & biomass concentration (biomass per unit volume of the sediment) \\
\hline$D$ & $m^{2} d^{-1}$ & oxygen effective diffusivity in the sediment \\
\hline$K_{O}$ & $\mathrm{~g} \mathrm{O} \mathrm{m}^{-3}$ & oxygen half-saturation constant \\
\hline$K_{S}$ & $\mathrm{~g} \mathrm{C} \mathrm{m}^{-3}$ & substrate half-saturation constant \\
\hline$k_{d}$ & $d^{-1}$ & microbial decay constant \\
\hline$k_{c}$ & $\mathrm{~m}^{3} \mathrm{~g}^{-1}$ cells $\mathrm{d}^{-1}$ & microbial competition constant \\
\hline$J$ & $g O \mathrm{~m}^{-2} \mathrm{~d}^{-1}$ & oxygen consumption rate (oxygen flux into the sediment) \\
\hline$J_{p}$ & $g O \mathrm{~m}^{-2} \mathrm{~d}^{-1}$ & oxygen consumption rate plateau \\
\hline$\mu$ & $d^{-1}$ & specific growth rate of the biomass \\
\hline$\mu_{m}$ & $d^{-1}$ & maximum specific growth rate of the biomass \\
\hline$O$ & $\mathrm{~g} \mathrm{O} \mathrm{m}^{-3}$ & oxygen concentration (oxygen per unit volume of the sediment) \\
\hline$O_{0}$ & $\mathrm{~g} \mathrm{O} \mathrm{m}^{-3}$ & oxygen concentration in the water overlying the sediment \\
\hline$R$ & $\mathrm{~g} \mathrm{O} \mathrm{g}^{-1}$ cells & microbial respiration coefficient \\
\hline$S$ & g C m ${ }^{-3}$ & $\begin{array}{l}\text { substrate concentration (degradable organic C per unit volume of the } \\
\text { sediment) }\end{array}$ \\
\hline$S_{0}$ & $\mathrm{~g} \mathrm{C} \mathrm{m}^{-3}$ & substrate concentration at the top sediment \\
\hline$V$ & $\mathrm{~m} \mathrm{~d}^{-1}$ & sediment growth rate \\
\hline$Y$ & g cells $g^{-1} \mathrm{C}$ & microbial yield coefficient \\
\hline$Z$ & $\mathrm{~m}$ & sediment depth \\
\hline
\end{tabular}

Kindred and Celia [1989] studied a multiple nutrient biodegradation model. The model incorporates both aerobic and anaerobic reactions, with several models of differing complexity presented for the aerobic case. Example simulations are presented for a variety of cases, ranging from onesubstrate, one-population aerobic degradation to multisubstrate, multipopulation anaerobic consor- 
tium degradation.

Wood et al. [1994] studied microbial mass growth in layered porous media with dissolved quinoline and oxygen. Only immobile (strongly attached to solid matrix) microorganisms were considered. The biodegradation rate was described by the Monod formula multiplied by a metabolic potential function based on a description of lag for batch systems by Kono [1968] and Wood and Dawson [1992]. For continuous steady-state systems, the metabolic lag may apparently be ignored.

Molz et al. [1986] modeled biodegradation in aquifers. Microorganisms grow in microcolonies attached to solid surfaces. Growth is limited by a lack of substrate (carbon and energy source) and oxygen. The modified Monod kinetics are used.

Molz and Widdowson [1988] revealed that the microbial-chemical activity (aerobic and anaerobic) is very sensitive to concentration distributions in aquifers. The depth profile of oxygen, computed for a small vertical dispersion of velocity, indicated the existence of two aerobic zones separated by a single anaerobic zone that was in agreement with three different site observations.

Zysset et al. [1994] used the biofilm concept to model nitrate and sulfate reduction in aquifers. The substrate half-saturation constant $K_{S}$ is regarded to be large enough to allow the Monod term to be simplified to a proportional law. The model involves bacterial decay. The authors note that the dead bacterial mass can in some cases serve as a carbon source for building up new biomass (though this factor has not been incorporated in the model).

Borden and Bedient [1986] simulated aerobic biodegradation of hydrocarbons and natural organics in aquifers using as few parameters as possible. The growth of microorganisms and removal of substrate (hydrocarbon) and oxygen were modeled using the modified Monod function

$$
\mu=\mu_{m} \frac{S}{K_{S}+S} \cdot \frac{O}{K_{O}+O}
$$

and the biodegradation kinetics

$$
\begin{aligned}
& d B / d t=\mu B-k_{d} B+k_{n} Y C, \\
& d S / d t=-\mu B / Y, \\
& d O / d t=-R \mu B,
\end{aligned}
$$

where $\mathrm{C}$ is the natural organic carbon content and $k_{n}$ is the first-order decay rate of natural organic carbon. Inorganic nutrients such as nitrogen, phosphorus, sulfur, and iron are all present in significant concentrations and are regarded to be non-limiting. The microorganisms are assumed to attach to solid surfaces [Thomas et al., 1985; Harvey et al., 1984] and to grow on the foreign hydrocarbon and naturally occurring organic carbon such as humic and fulvic acids (the degradation of natural organic carbon is described by the term $k_{n} Y C$ ). These compounds decay very slowly, but due to 
their relatively high concentrations can support a significant bacterial population.

\section{A REVISED BIOLOGICAL MODEL FOR BENTHIC SEDIMENTS}

The following peculiarities of benthic sediments are important for modeling aerobic biodegradation and are treated in the developments below as assumptions.

\section{Assumptions of the model}

1. Microbial cells attach to the solid matrix and are possibly grouped in microcolonies but with no appreciable impediment to the transport of nutrients and oxygen to cells because of the small sizes of the colonies. Following Wood et al. [1994], such a system can be described on the basis of the macroscopic approach.

2. Being attached to a detritus particle, heterotrophic bacteria can use two sources of organic matter: that emanating from the particle and that dissolved in the water. The bacteria primarily utilize the particle organic matter as more labile and then the soluble components (mainly refractory, such as humic and fulvic acids) adsorbed onto the particle surface from the water [Khailov, 1971; Drabkova, 1981]. Thus, dissolved organic matter provides the sediments with refractory components, and settling detritus with labile ones. Therefore, in our modeling we will consider only particulate organic matter (partially degraded detritus particles) included in the sediment solid matrix; it is therefore treated as an immobile.

3. The substrate includes organic compounds with different degradation rates. In eutrophic and mesotrophic environments, the oxygen is exhausted primarily from oxidizing mostly labile compounds [Kerner and Gramm, 1995]. The remaining, more refractory compounds are degraded by facultative and anaerobic bacteria in the underlying sediments. In oligotrophic environments, labile organics have already been decomposed in the water column, so that the sediment surface is reached only by slowly degrading refractory compounds. Thus, only a narrow part of the entire spectrum of organic compounds in sediments is aerobically oxidized, and it can be characterized by an average biodegradation rate. This allows the aerobically degradable organics to be approximately described as a single substrate.

4. The degradability of organic matter is weakly reduced with depth within the aerobic zone because of its low thickness, whereas this reduction is very significant in anoxic sediments of high thickness under the action of anaerobic bacteria [Middelburg, 1989].

5. The degradation of refractory organics by facultative and anaerobic bacteria generates soluble reduced chemicals which emanate into the aerobic zone and oxidize there with oxygen. For a 
sufficiently high oxygen content in the overlying water, the oxygen consumption for oxidizing the reduced chemicals in the sediments is typically small compared to respiration of aerobes [Belanger, 1981].

6. Biogenic substances are present in concentrations sufficient to be non-limiting [Borden and Bedient, 1986]. The growth of microbial mass is only limited by a lack of substrate and oxygen according to the simple expression (3).

7. Benthic invertebrates intensify oxygen transfer into the sediments. A marked change is observed at a density of more than $250 \mathrm{org} / \mathrm{m}^{2}$ [Graneli, 1979]. We will study only those systems which have smaller densities of invertebrates.

8. The community of aerobic microorganisms consisting of different microbial groups can been described as a single population provided there is no large-scale spatial separation of the groups. The biomass density $B$ of this community involves only living, active cells and obeys the equation $d B / d t=F(B) B$ with a logistic type trophic function [Howell, 1983; Svirezhev, 1987]

$$
F(B)=\mu-k_{d}-k_{c} B,
$$

where $\mu$ describes the growth of biomass; $k_{d}$ concerns the decrease of biomass due to endogenous respiration and microbial die-away [Fuhrman and Noble, 1995]; and $k_{c}$ characterizes the competition between the microbial groups. In addition, the factor $k_{c}$ can effectively account for the predator-prey relations between protozoa and bacteria [Starink et al., 1996]. The simpler, Malthusian trophic function $F(B)=\mu-k_{d}$ cannot be used here, because it leads to instability of the community owing to uncontrollable biomass growth at $\mu>k_{d}$ or decay at $\mu<k_{d}$.

9. The benthic community adapts to changes in the ambient conditions within a few days to a few weeks depending on the type and magnitude of the changes [Truex et al., 1992]. Due to this lag, diurnal variations in temperature and oxygen content [Jeppesen, 1982], as well as in the rate of settling organic matter can be averaged. Such smoothed-out ambient parameters vary slowly (with a seasonal trend) and may be considered as quasi-steady. The steady-state ambient conditions lead to the establishment of a local steady state in the microbial community, at which $d B / d t=0$ at every point of the sediment, or equivalently

$$
F(B)=\mu-k_{d}-k_{c} B=0 .
$$

10. At high enough concentration of cells, their die-away is caused mainly by the competition effect, so that of the two quantities $k_{d}$ and $k_{c} B$, the latter predominates. Suppose that the condition $k_{d}$ $<<k_{c} B$ is valid almost throughout the entire aerobic zone, except for the aerobic-anaerobic interface where $B$ tends to zero. Under the local equilibrium (6), this condition is equivalent to 


$$
\mu>k_{d} \text {. }
$$

\section{Mathematical statement of the model}

According to the above-listed considerations, we may write the following steady-state model involving the balances of biomass, substrate, and oxygen:

$$
\begin{gathered}
\mu-k_{c} B=0, \\
V \frac{d S}{d Z}=-\frac{\mu B}{Y}, \\
D \frac{d^{2} O}{d Z^{2}}-R \mu B=0,
\end{gathered}
$$

where equation (8) follows from (6) and (7) and the specific growth rate $\mu$ is determined by (3). At the water-sediment interface, the concentrations of oxygen and substrate are maintained constant:

$$
O(0)=O_{0}, \quad S(0)=S_{0}
$$

Equation (10) requires an additional boundary condition, as such the condition at infinity being taken:

$$
O \rightarrow 0, \quad \frac{d O}{d Z} \rightarrow 0 \quad \text { at } Z \rightarrow \infty
$$

The flux of oxygen from the overlying water into the sediment is defined as

$$
J=-D \frac{d O}{d Z}(0)
$$

The problem (8)-(12) is first reduced to a dimensionless form as described in Appendix 1 and then is solved with the use of analytical and numerical methods as presented in Appendix 2.

\section{RESULTS}

\section{Oxygen consumption rate}

It is proved in Appendices 1 and 2 that the oxygen flux into the sediment can generally be described as

$$
J=J_{p} f\left(\lambda, 2 s_{0}^{-2} q\left(o_{0}\right)\right)
$$

and in the special cases as 


$$
\begin{aligned}
& J \approx J_{p} \min \left\{1, s_{0}^{-1} \sqrt{2 q\left(o_{0}\right)}\right\} \quad(\lambda<<1), \\
& J \approx J_{p} f_{1}\left(\kappa^{-2} q\left(o_{0}\right)\right) \quad(\lambda>>1),
\end{aligned}
$$

where the functions $f$ and $f_{1}$ are defined as the solutions of equations (A15) and (A17), respectively (Appendix 2). The quantity $J_{p}$ and the dimensionless groupings $\lambda, \kappa, s_{0}$ and $o_{0}$ can be expressed through the initial model parameters (listed in Table 1):

$$
J_{p}=R Y V S_{0}, \quad \lambda=\frac{K_{S}}{S_{0}}, \quad s_{0}=\frac{Y V S_{0}}{\mu_{m}} \sqrt{\frac{R k_{c}}{D K_{O}}}, \quad \kappa=\lambda s_{0}, \quad o_{0}=\frac{O_{0}}{K_{O}} .
$$

The function $q$ in (13)-(15) is defined as

$$
q\left(o_{0}\right)=o_{0}-2 \ln \left(o_{0}+1\right)+1-\frac{1}{o_{0}+1} .
$$

When the values of the initial model parameters are known, the dependence of $J$ on $O_{0}$ is easily calculated using the relations obtained. Usually, such parameters as $\mu_{m}, k_{c}, K_{O}$, and $K_{S}$ are not known. Hence to calibrate the model, we need to first solve the reciprocal problem formulated as: find the parameters $J_{p}, \lambda$, so, and $K_{O}$ using the empirical relationship $J$ vs. $O_{0}$. On solving this problem, one can use the results obtained and some additional information to estimate the initial model parameters. The model calibration procedure is described in Appendix 3.

\section{Treatment of experimental data}

Below, we will consider the calibration of the model for different experimental systems. The information available for these systems is presented in Table 2. The lack of required information is resolved with data taken from other sources. For each system, we have accepted the same values of the following parameters :

$$
R Y=2.67 \mathrm{~g} \mathrm{O} / \mathrm{g} \mathrm{C}, Y=0.5 \mathrm{~g} \text { cells } / \mathrm{g} \mathrm{C}, D=1.0 \mathrm{~cm}^{2} / \mathrm{d} .
$$

The value of $R Y$ is taken from equation (1). From measurements for biofilms, $Y$ is within the range 0.28-0.54 [Stouthamer, 1977; Characklis and Marshall, 1990]. The diffusivity $D=1.4$ for a seston layer at the water-sediment interface [Kerner and Gramm, 1995]; $D=0.16$ for grey river silts and 1.4 for silty sands [Brekhovskikh et al., 1990]. The effective diffusivity increases by 1.5-2 times at oligochetta densities of $\sim 10^{4} \mathrm{org} / \mathrm{m}^{2}$.

The data (18) and in Table 2 will be applied solely to estimating the initial model parameters, not to calibrating the model. The calibration requires only the empirical relationship $J$ vs. $O_{0}$. 
Table 2. Characteristics of the reference experimental systems

\begin{tabular}{|c|c|c|c|}
\hline Quantity & \begin{tabular}{l}
\multicolumn{1}{c}{ System FM } \\
[Fillos \& Molof, 1972] \\
"Benthal deposits" \\
(wastewater sludge + \\
fine sand), continuous \\
lab system (Run 1)
\end{tabular} & $\begin{array}{l}\text { System B } \\
\text { [Belanger, 1981] } \\
\text { Hypereutrophic lake } \\
\text { benthic sediments, } \\
\text { continuous lab system } \\
\text { (Station 2) }\end{array}$ & $\begin{array}{l}\text { System D } \\
\text { [Dzyuban, 1987] } \\
\text { Mesotrophic reservoir } \\
\text { benthic sediments, } \\
\text { batch lab system (4- } \\
\text { hour exposure) }\end{array}$ \\
\hline$J_{p}, \mathrm{~g} \mathrm{O} \mathrm{m}^{-2} \mathrm{~d}^{-1}$ & $7.20^{\mathrm{a}}$ & $3.05^{\mathrm{a}}$ & $0.095^{\mathrm{a}}$ \\
\hline DS, \% & 63.4 & $3.4^{\mathrm{b}}$ & - \\
\hline VS, \% of DS & 6.46 & 57.1 & - \\
\hline $\mathrm{SG}, \mathrm{g} / \mathrm{cm}^{3}$ & 1.54 & $1.5^{\mathrm{c}}$ & - \\
\hline $\mathrm{BOD}_{\mathrm{vs}}, \mathrm{g} \mathrm{O} / \mathrm{g} \mathrm{VS}$ & 0.355 & - & - \\
\hline $\mathrm{COD}_{\mathrm{vs}}, \mathrm{g} \mathrm{O} / \mathrm{g} \mathrm{VS}$ & 1.88 & - & - \\
\hline Chem, \% of $J$ & $\sim 20^{\mathrm{h}}$ & 12 & $10-15$ \\
\hline TOC, $10^{3} \mathrm{~g} \mathrm{C} / \mathrm{m}^{3}$ & $35^{\mathrm{d}}$ & $11^{\mathrm{e}}$ & 12 \\
\hline LOC/TOC, \% & $24^{\mathrm{f}}$ & $15^{\mathrm{g}}$ & $10^{\mathrm{c}}$ \\
\hline$S_{0}=\mathrm{LOC}, 10^{3} \mathrm{~g} \mathrm{C} / \mathrm{m}^{3}$ & 8.4 & 1.7 & 1.2 \\
\hline$V, \mathrm{~mm} / \mathrm{d}$ & $0.32^{\mathrm{i}}$ & $0.66^{\mathrm{i}}$ & $0.029^{\mathrm{i}}$ \\
\hline $\mathrm{ZP}, \mathrm{g} \mathrm{O} / \mathrm{m}^{3}$ & 0 & 1.1 & 0.8 \\
\hline $\mathrm{ID}, \mathrm{org} / \mathrm{m}^{2}$ & 0 & 172 & 0 \\
\hline
\end{tabular}

Key:

DS = dry solids

Chem $=$ chemical oxygen consumption rate

VS = volatile solids TOC $=$ total organic carbon

$\mathrm{SG}=$ sediment specific gravity

LOC = labile organic carbon

$\mathrm{BOD}_{\mathrm{vs}}=$ biochemical oxygen demand per g $\mathrm{ZP}=$ zero point ( $\max \mathrm{O}_{2}$ conc. retaining $J=0$ )

VS ID $=$ invertebrates density

$\mathrm{COD}_{\mathrm{vs}}=$ chemical oxygen demand per g VS

${ }^{\text {a }}$ Estimated using the $J$ vs. $O_{0}$ plots from the reference works.

${ }^{\mathrm{b}}$ No data for Station 2. For Station 6, water content in the sediment was 96.6\%.

${ }^{\mathrm{c}}$ Accepted for the calculations.

${ }^{\mathrm{d}}$ Calculated as TOC $=\mathrm{SG} \times \mathrm{DS} \times \mathrm{VS} \times \mathrm{COD}_{\mathrm{vs}} \times(1-\mathrm{Chem}) / R Y$.

${ }^{\mathrm{e}}$ Calculated using the previous formula at $\mathrm{COD}_{\mathrm{vs}} \times(1-\mathrm{Chem})=1$.

${ }^{\mathrm{f}}$ Calculated as the ratio $\mathrm{BOD}_{\mathrm{vs}} / \mathrm{COD}_{\mathrm{vs}} /(1-\mathrm{Chem})$.

${ }^{\mathrm{g}}$ Estimated for water of some eutrophic lakes by Kuznetsov [1970]. Since the lake in question is extremely shallow (to $2 \mathrm{~m}$ ), the same organic matter content has been taken for its sediments.

${ }^{\mathrm{h}}$ Oxygen demand for oxidizing dissolved organics and chemicals emanating from the underlying sediment.

${ }^{\mathrm{i}}$ Calculated as $V=J_{p} /\left(R Y S_{0}\right)$. 


\section{System FM}

Fillos and Molof [1972] investigated the oxygen consumption of a benthic sediment in a continuous flow-through laboratory system. The benthic sediment (sludge) was prepared as a mixture of raw primary wastewater solids, taken from two wastewater treatment plants, and fine sand. The sludge was incubated in aerated water for a period of more than a month, being remixed about twice a week to remove the most readily soluble matter. Then the sludge was transferred into reactors with a continuous flow of tap water at the rate needed to maintain a constant oxygen concentration in the overlying water. Just before transfer into reactors, the sludge was characterized by the composition presented in Table 2. This system is unsteady because there is no organic carbon flux into the benthic sediment. In fact, what takes place is a gradual decay of the initially accumulated organic matter. However by virtue of its slow degradation, the non-equilibrium nature of the process is insignificant at relatively small times. The experimental relationship $J_{i}$ vs. $O_{0 i}$ has a large dispersion. Therefore, the model calibration procedure (see Appendix 3) yields several different local minima for the objective function $\sigma_{x}$ (A22), close in magnitude but dramatically distinguished by the values of the control parameters (Table 3). For the two sets of control parameters, the oxygen consumption as a function of the dissolved oxygen is plotted on Fig. 1.

Table 3. The model control parameters and the standard deviation (SD) for the reference experimental systems

\begin{tabular}{|l|ccc|c|c|c|c|c|c|}
\hline \multirow{2}{*}{ Quantity } & \multicolumn{3}{|c|}{ System FM } & \multicolumn{3}{c|}{ System B } & \multicolumn{3}{c|}{ System D } \\
\cline { 2 - 10 } & $\min 1$ & $\min 2$ & eq.(15) & $\min 1$ & $\min 2$ & eq.(15) & $\min 1$ & $\min 2$ & eq.(15) \\
\hline $\mathrm{SD}, \sigma_{x}$ & 0.111 & 0.113 & 0.113 & 0.079 & 0.073 & 0.073 & 0.039 & 0.022 & 0.022 \\
$\lambda$ & 0 & 112.6 & $\infty$ & 0 & 24.6 & $\infty$ & 0 & 11.3 & $\infty$ \\
$s_{0}$ & 4.99 & 0.0429 & 0 & 2.69 & 0.0163 & 0 & 30.5 & 0.966 & 0 \\
$\kappa=\lambda s_{0}$ & 0 & 4.83 & 4.84 & 0 & 0.401 & 0.383 & 0 & 10.9 & 10.8 \\
$K_{O}, \mathrm{~g} \mathrm{O}^{3}$ & 0.105 & 0.0696 & 0.0701 & 0.293 & 1.36 & 1.45 & 0.00382 & 0.0133 & 0.0149 \\
\hline
\end{tabular}

Key: A column 'min i' characterizes the ith minimum of SD (its magnitude and corresponding values of the control parameters). A column 'eq.(15)' characterizes the minimum of SD at $\lambda=\infty$ and corresponding values of the control parameters, computed using equation (15). 


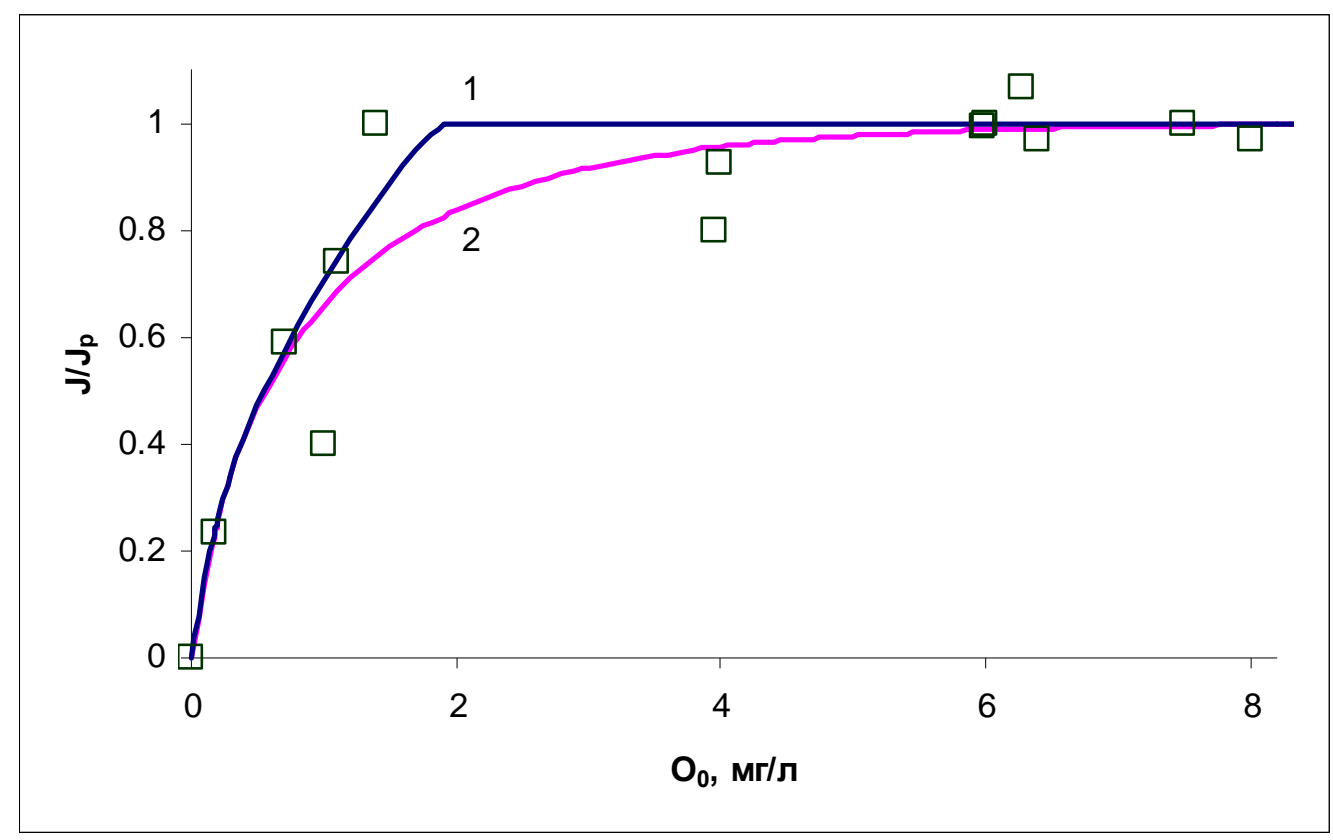

Fig. 1. System FM: the oxygen consumption rate as a function of the oxygen concentration in the overlying water at $\lambda=0$ (curve 1) and $\lambda=\infty$ (curve 2); $\square$ experimental points. The appropriate values of control parameters are presented in Table 3 in columns 'min 1' for curve 1 and 'eq.(15)' for curve 2. The curve associated with column 'min 2' coincides with curve 2.

\section{System B}

Belanger [1981] determined the oxygen consumption of benthic sediments of an extremely shallow, hypereutrophic lake using laboratory core-uptake (batch) and flow-through (continuous) system techniques. The sediment used was characterized by the composition presented in Table 2. Using the core-uptake method, the oxygen consumption was indicated to be primarily biological $88 \%$, of which $25 \%$ was bacterial respiration and $63 \%$ was non-bacterial (fungi and protozoa). The remaining $12 \%$ was chemical oxidation. Certain invertebrates can increase the rates of exchange of interstitial water and water overlying the sediments [Edwards and Rolley, 1965]. For the system in question, the benthic invertebrate densities were low compared to what was observed by Brekhovskikh et al. [1990] $\left(1 \times 10^{4}\right.$ to $\left.5 \times 10^{4} \mathrm{org} \mathrm{m}^{-2}\right)$ and Graneli [1979] (250 to $\left.2700 \mathrm{org} \mathrm{m}^{-2}\right)$, so that the diffusivity would be insignificantly affected by invertebrates.

In the flow-through system, the lake sediment covered with lake water was incubated for 3 days, and then the flow was run through the system for at least 1 day. Over this period, the labile organics had degraded in part. This system is unsteady like the previous one, but may be considered as steady over relatively small times. 
The feature of the data is that zero oxygen consumption is reached not at zero oxygen concentration in the overlying water but at about $1.1 \mathrm{~g} \mathrm{O} / \mathrm{m}^{3}$ (the zero point in Table 2). At this or lower concentrations the aerobic microbial activity may decrease sharply, but it is not quite clear why oxygen is not consumed by the oxidation of chemicals. This effect is not observed in System FM, i.e. its zero point is zero. Since the zero point effect is of indefinite nature and not involved in the model, it was decided to shift the scale of oxygen concentrations to the zero point value. Thus, the model calibration was performed using the $J_{i}$ vs. $O_{0 i}$ data shifted by $1.1 \mathrm{~g} \mathrm{O} / \mathrm{m}^{3}$ on the abscissa axis. The calibration results are presented in Table 3. The oxygen half-saturation constant is fairly high compared to that for System FM, therefore the plateau is reached at larger oxygen concentrations. The theoretical curve and the experimental data of oxygen consumption are juxtaposed in Fig. 2.

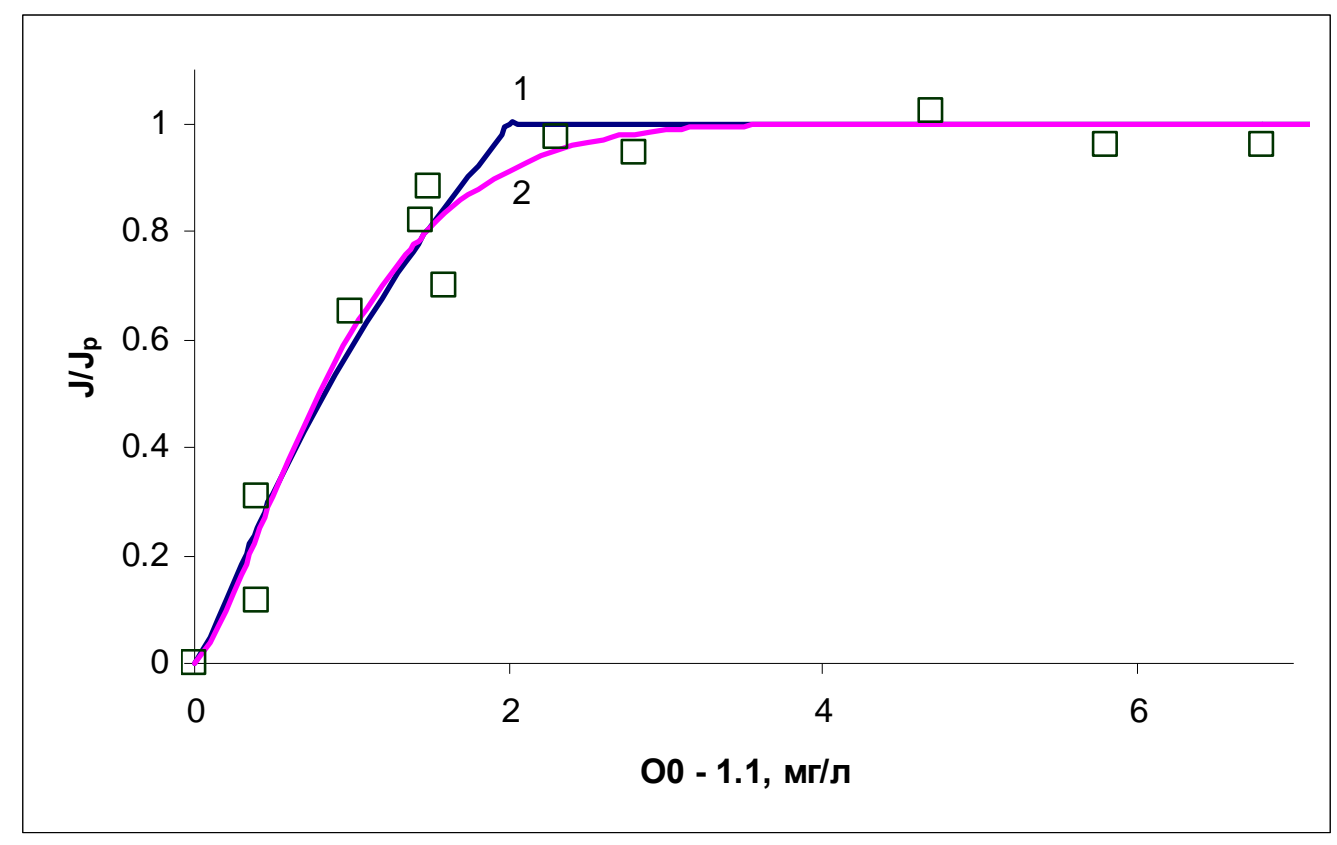

Fig. 2. System B (see caption to Fig. 1).

\section{System $D$}

Dzyuban [1987] investigated the benthic sediments of a mesotrophic reservoir. The oxygen consumption was determined in closed tubes using the core-uptake method. The tubes were filled with silt and lake water with a known oxygen concentration in the range $0.8-12 \mathrm{~g} / \mathrm{m}^{3}$. The effect of the oxygen concentration in the overlying water on the sediment oxygen consumption was determined in two runs with different exposure times: 4 and 24 hours. In the 24-hour run, the oxygen concentration varied substantially. Since the model considers steady-state modes, this run is improper for treatment by the model. In the 4-hour run, the oxygen concentration in the water negligi- 
bly varied. Therefore this run was chosen to calibrate the model. As in the study by Belanger [1981], this run indicated a residual oxygen concentration (of about $0.8 \mathrm{~g} / \mathrm{m}^{3}$ ), below which oxygen was not consumed that was explained as the manifestation of a physiological zero (it is considered that at such small concentrations the microbial activity is negligible). This effect was taken into account in calibrating the model by shifting the scale of the oxygen concentration by $0.8 \mathrm{~g} / \mathrm{m}^{3}$. The measurements indicated that $10-15 \%$ of the oxygen was consumed by chemical oxidation. As the labile organic matter was depleted, the intensity of aerobic degradation decreased, but over a 4 hour exposure it may be neglected. Thus, although the measurements were conducted in batch conditions, the main parameters varied only weakly. This permitted us to treat these data using the steady-state model. The results of the calibration are presented in Table 3. The $J$ vs. $O_{0}$ plot in comparison with the experimental points is depicted in Fig. 3.

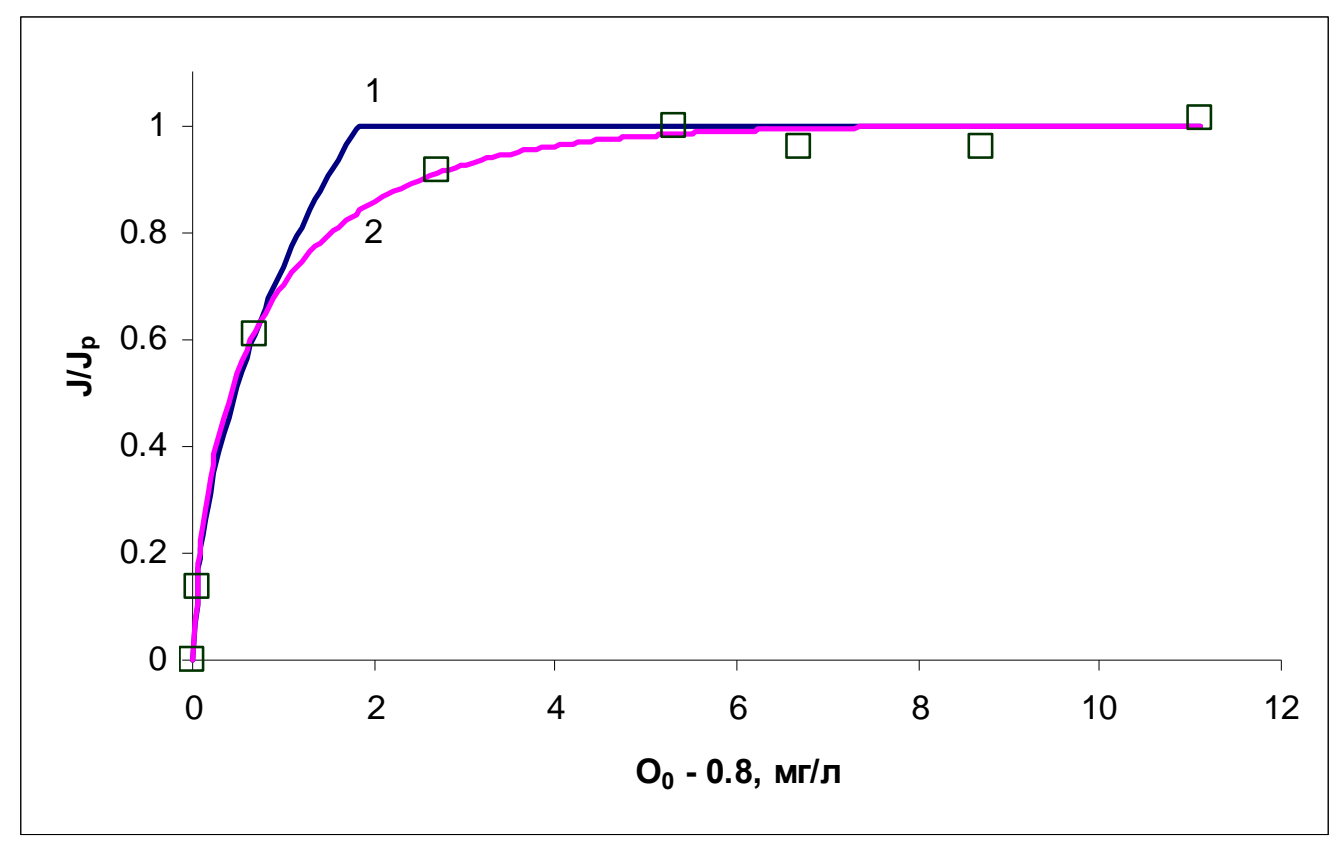

Fig. 3. System D (see caption to Fig. 1).

\section{DISCUSSION}

\section{Comparison of the calibrated models}

Table 3 shows that for System $\mathrm{D}$ the standard deviation is minimum at $\lambda=11.3$. However it is not quite clear whether this is the global minimum because large values of $\lambda$ are nondistinguishable by $\sigma_{x}$ firstly because of the low accuracy of the experimental data. Another reason 
for the insensitivity to $\lambda$ variations are different biodegradation rates of the components of natural organic matter [Hargrave and Phillips, 1989; Middelburg, 1989].

For Systems FM and B, the minima determined are almost degenerate (having close magnitudes). At the available accuracy of experimental data, it is difficult to decide which of them is global.

One of the minima obtained corresponds to $\lambda=0$ and the other to $\lambda>>1$. This inclines us to use the special cases (14) and (15) instead of the general dependence (13) and thus to reduce the number of control parameters to two (in either case) for simplifying the calibration of the model. Columns 'min 1' in Table 3 present the calibration results, identical for the general case and the first special case (at $\lambda=0$ ). Columns 'eq.(15)' present the results of the second special calibration (at $\lambda>>1$ ). Note that values of $\kappa$ presented in columns 'min 2' and 'eq.(15)' are reasonably close to one another.

It is typical that $K_{O}<<O_{0}$ for the majority of the cases. Small values of $K_{O}$ compared to the typical oxygen concentration $O_{0}$ in the overlying water testify that the biomass specific growth rate (3) is independent of the oxygen concentration almost throughout the entire aerobic zone except at the lower boundary of the zone where the oxygen concentration is comparable with $K_{O}$.

\section{Calculation of decay time}

To interpret the cases $\lambda=0$ and $\lambda>>1$, we should bear in mind the following arguments. In a medium of labile organics, the equilibrium microbial abundance is high and the cells develop with a lack of substrate corresponding to $K_{S}>>S_{0}$, or $\lambda>>1$. In a medium of refractory (with no labile) organics, the equilibrium microbial abundance is small because of slow metabolism; now the substrate is present in excess, yielding $K_{S}<<S_{0}$, or $\lambda<<1$.

Each case is characterized by a certain decay time, small in the first case and large in the second. To estimate the decay times, it is necessary to analyze equation (9). The right-hand side presents the decay rate

$$
\left(\frac{d S}{d t}\right)_{\text {decay }}=-\frac{\mu B}{Y}=-\frac{\mu^{2}}{k_{c} Y} .
$$

The decay time $\tau$ can be defined in keeping with (19) and (3):

$$
\frac{S_{0}}{\tau}=\frac{\mu_{m}^{2}}{k_{c} Y} \quad \text { at } \quad \lambda=0 \text { and } \quad \frac{S_{0}}{\tau}=\frac{\mu_{m}^{2}}{k_{c} Y}\left(\frac{S_{0}}{K_{s}}\right)^{2} \text { at } \lambda>>1 \text {, }
$$

from whence 


$$
\tau=\frac{Y S_{0} k_{c}}{\mu_{m}^{2}} \quad \text { at } \quad \lambda=0 \text { and } \tau=\frac{K_{S}^{2} Y k_{c}}{S_{0} \mu_{m}^{2}} \text { at } \lambda>>1 .
$$

These equations include the two unknown quantities $k_{c}$ and $\mu_{m}$, which are present as the ratio $k_{c} / \mu_{m}^{2}$. This ratio can be expressed through $s_{0}$ (at $\left.\lambda=0\right)$ and $\kappa($ at $\lambda>>1)$ using (16):

$$
\frac{k_{c}}{\mu_{m}^{2}}=\frac{D K_{O}}{R}\left(\frac{s_{0}}{Y V S_{0}}\right)^{2} \text { at } \lambda=0 \text { and } \frac{k_{c}}{\mu_{m}^{2}}=\frac{D K_{O}}{R}\left(\frac{\kappa}{Y V K_{S}}\right)^{2} \text { at } \lambda>>1 \text {. }
$$

Substituting (21) into (20), we get:

$$
\tau=s_{0}^{2} \frac{D K_{O}}{R Y V^{2} S_{0}} \quad \text { at } \lambda=0 \text { and } \tau=\kappa^{2} \frac{D K_{O}}{R Y V^{2} S_{0}} \quad \text { at } \lambda>>1 \text {, }
$$

All the quantities in (22) are known, which allows the decay times to be computed (for each system, the first value corresponds to $\lambda=0$ and the second value to $\lambda>>1$ ): $\tau=0.11$ and $0.071 \mathrm{~d}$ (System FM), $\tau=0.10$ and $0.010 \mathrm{~d}$ (System B), $\tau=130$ and $6.2 \mathrm{~d}$ (System D).

The results for Systems FM and B have no meaning because the systems are unsteady. Their sediments are not fed by organic matter, i.e. in fact $V=0$, whereas the calculations used the steadystate values of $V$ (see Table 2). Incidentally, for such a significant steady-state flux of organics into the sediments, the conditions there will be rather anaerobic. For System D, both decay times make sense. Thus, the findings (22a) indicate that it is most valid to use the batch technique of measurements for studying limnetic benthic sediments.

According to (22a), smaller decay times correspond to $\lambda>>1$. This confirms again that $\lambda>>1$ relates to labile organics and $\lambda=0$ to refractory.

\section{Selecting the proper model calibration}

In studying a real system, one of the two cases $(\lambda=0$ or $\lambda>>1)$ must be selected. This can be done by determining the interrelation between biomass and organic matter content. Bearing in mind that $K_{O}<<O_{0}$, we derive from (3):

$$
\mu \approx \mu_{m} \text { at } \lambda=0 \text { and } \mu \approx\left(\mu_{m} / K_{S}\right) S \text { at } \lambda>>1 .
$$

Equation (8) implies $B=\mu / k_{c}$ that in accord with (23) gives:

$$
\begin{aligned}
& B \approx \frac{\mu_{m}}{k_{c}} \text { at } \lambda=0, \\
& B \approx \frac{\mu_{m}}{k_{c} K_{S}} S \text { at } \lambda>>1 .
\end{aligned}
$$


From the evidence available for limnetic sediments, one may conclude that the biomass in the top silt is proportional to the organic matter content: $B=\beta S$ (however it is unknown whether this relation is of frequent occurrence). Drabkova [1981] found that the proportionality coefficient $\beta$ can reach 0.025 or even 0.078 . This evidence is in agreement with (25) that allows us to choose the latter of the cases $\lambda=0$ and $\lambda>>1$ and to set the relation:

$$
\frac{\mu_{m}}{k_{c} K_{S}}=\beta
$$

We can find the parameters on the left-hand side of (26) using (16) and write the expression:

$$
\kappa=\frac{Y V K_{S}}{\mu_{m}} \sqrt{\frac{R k_{c}}{D K_{O}}} .
$$

Excluding $\mu_{m}$ from (26) and (27), we get:

$$
k_{c}=\frac{R}{D K_{O}}\left(\frac{Y V}{\beta \kappa}\right)^{2} .
$$

The estimates found for $k_{c}$ and $\mu_{m} / K_{S}=\beta k_{c}$ at $\beta=0.05$ are shown in Table 4.

Table 4. The biomass growth and decay parameters (at $\lambda>>1$ )

for the reference experimental systems

\begin{tabular}{|c|c|c|}
\hline System & $\begin{array}{c}\text { Microbial competition constant } \\
k_{c}, \mathrm{~m}^{3} \mathrm{~g}^{-1} \text { cells } \mathrm{d}^{-1}\end{array}$ & $\begin{array}{c}\text { Biomass growth rate parameter } \\
\mu_{m} / K_{s}, \mathrm{~m}^{3} \mathrm{~g}^{-1} \mathrm{C} \mathrm{d}^{-1}\end{array}$ \\
\hline FM & 0.33 & 0.017 \\
B & 11 & 0.55 \\
D & $2.6 \times 10^{-3}$ & $1.3 \times 10^{-4}$ \\
\hline
\end{tabular}

From the results obtained, only those for System D are in agreement with the common notion. To begin with, a sediment growth rate of $1.0 \mathrm{~cm} / \mathrm{yr}$ (cf. Table 2) is typical for mesotrophic environments. The values of $V$ found for Systems FM and B are too high and must lead to anaerobic conditions in the sediments. Therefore, we have to admit that, though the derived dependence $J\left(O_{0}\right)$ is also applicable to these systems, the values of the initial model parameters are unrealistic. This concerns the decay times which are too small (cf. (22a)), as well as the parameters of growth and decay of biomass (see Table 4) which are conversely too large. For systems enriched like FM and B 
with labile organic matter, the decay times should be a few days to several weeks [Kerner and Gramm, 1995; Newell et al., 1981; Pavlyutin and Ostapenya, 1972; Hargrave and Phillips, 1989].

As to the biomass specific growth rate $\mu_{m}$, this requires knowing $K_{S}$. To estimate $K_{S}$, it is necessary, recalling the formula $K_{S}=\lambda S_{0}$, to use $S_{0}$ from Table 2 and $\lambda$ from Table 3 (columns 'min 2'), though one might doubt the latter because the $\sigma_{x}$ minima are difficult to discriminate. This results in $K_{S}=$ 0.946, 0.0418, 0.0135 (in $10^{6} \mathrm{~g} \mathrm{C} / \mathrm{m}^{3}$ ) for Systems FM, B, and D, respectively. Then Table 4 yields: $\mu_{m}=1.6 \times 10^{4}, 2.3 \times 10^{4}, 1.8 \mathrm{~d}^{-1}$, respectively. Button [1985], MacQuarrie et al. [1990], Alvarez et al. [1991], and Chen et al. [1992] found that for freshwater and groundwater bacteria the $\mu_{m}$ have to be within the range 0.01-9.9 $\mathrm{d}^{-1}$. Only the last value of $\mu_{m}\left(1.8 \mathrm{~d}^{-1}\right)$ falls within this range, the other two are fairly unrealistic. The reason for such evident discrepancy for Systems FM and B is because of their unsteadiness, as was mentioned above.

The results for System D are all in agreement with the evidence for mesotrophic environments. Let us write out separately the values of the initial model parameters obtained for this system:

$$
\begin{aligned}
& K_{O}=1.49 \times 10^{-2} \mathrm{~g} \mathrm{O} / \mathrm{m}^{3}, K_{S}=1.35 \times 10^{4} \mathrm{~g} \mathrm{C} / \mathrm{m}^{3}, \mu_{m}=1.8 \mathrm{~d}^{-1} \text {, } \\
& k_{c}=2.6 \times 10^{-3} \mathrm{~m}^{3} \mathrm{~g}^{-1} \text { cells } \mathrm{d}^{-1}, V=29 \mu \mathrm{m} / \mathrm{d} \text {. }
\end{aligned}
$$

The scales of basic quantities can be found using (A2) (Appendix 2):

$$
Z_{*}=15 \mu \mathrm{m}, S_{*}=1.24 \times 10^{3} \mathrm{~g} \mathrm{C} / \mathrm{m}^{3}, B_{*}=6.9 \times 10^{2} \mathrm{~g} \text { cells } / \mathrm{m}^{3} \text {. }
$$

The depth profiles of oxygen, substrate, and biomass were determined numerically as described in Appendix 2. The profiles obtained for System D at $O_{0}=3 \mathrm{~g} \mathrm{O} / \mathrm{m}^{3}$ and $S_{0}=1.2 \times 10^{3} \mathrm{~g} \mathrm{C} / \mathrm{m}^{3}$ are depicted in Fig. 4. Comparison with the profiles at higher values of $O_{0}$ (Fig. 5) shows that the thickness of the aerobic zone increases with the oxygen concentration in the overlying water, especially when $O_{0}$ passes into the $J\left(O_{0}\right)$ plateau region. This is caused by an excess of oxygen relative to the degradable organic content.

In developing the model, we have assumed $\mu>>k_{d}$ that should be verified. Truex et al. [1992] showed that the decay rate can in some instances be nearly equal to zero ( $k_{d} \approx 0$ ). The calibration of different models indicated that $k_{d}$ did not exceed $0.02 \mathrm{~d}^{-1}$ [Borden and Bedient, 1986; Molz et al., 1986; Molz and Widdowson, 1988; Zysset et al., 1994]. These models did not involve the competition effect (i.e. did not include the term $k_{c} B$ in (5)), therefore for our model this value of $k_{d}$ should be regarded as overestimated. Nevertheless, for System D as found above, $\mu_{m}=1.8 \mathrm{~d}^{-1}$ and $\lambda=$ 11.3, then $\mu \approx \mu_{m} \lambda^{-1} \approx 0.2 \mathrm{~d}^{-1}$ for the top sediment that is one order of magnitude greater than $k_{d}$. This confirms the assumption adopted.

Now consider how the decay rate of organic matter depends on its content. As noted above, the chemical models suppose that $d S / d t \propto S$. The biological models give $d S / d t \propto \mu B$ according to (4). 
The same result as the chemical models, we can obtain from our model by two ways: (1) to suppose that the kinetics are substrate-limiting (then $\mu \propto S$ ) and the biomass is constant; or (2) to suppose that the biomass is proportional to the substrate content $(B \propto S)$ and the kinetics are not limited by the substrate (i.e. $\mu$ is independent of $S$ ). However, neither of these ways can provide an equilibrium in the microbial community (since there is no transport of biomass in benthic sediments unlike in flow-through systems). They give rise either to unbounded growth of biomass or its decay to total extinction. Neither of the scenarios is actual. As (8) shows, an equilibrium is only possible when $B=\mu / k_{c}$. But in this case, $\mu$ and $B$ are either both independent of $S$, yielding the result that $d S / d t$ is invariant of $S$ (this is related to the above-mentioned case $\lambda=0$ ), or both proportional to $S$, yielding $d S / d t \propto S^{2}$ (the case $\lambda>>1$ ). Thus, the dependence $d S / d t \propto S$ adopted in the chemical models is quite impossible for systems with no transport of microbial cells and with a local equilibrium in the microbial community.

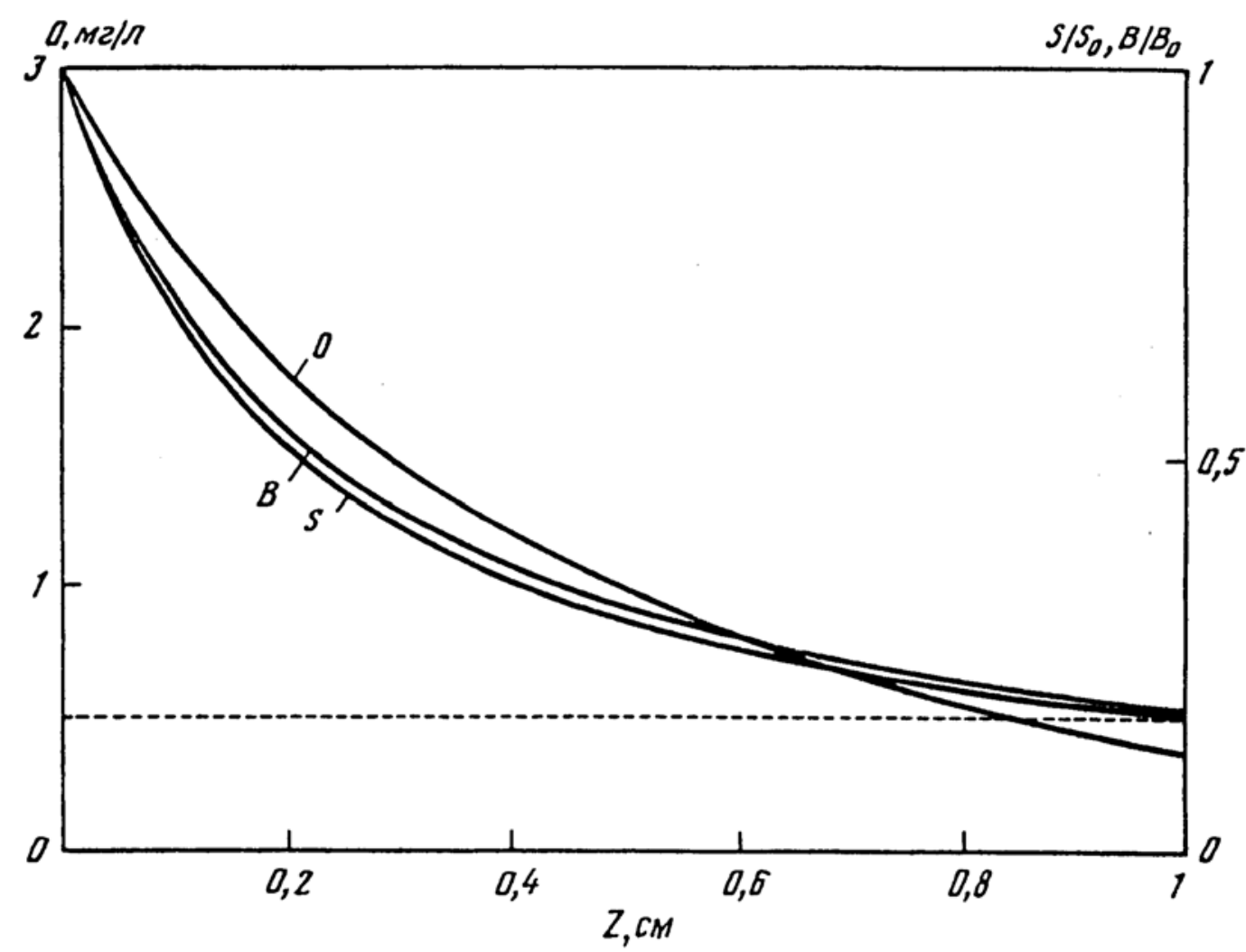

Fig. 4. Depth profiles of oxygen, substrate, and biomass for System D at $S_{0}=12 \times 10^{3} \mathrm{~g} \mathrm{C} / \mathrm{m}^{3}$ and $B_{0}$ $=56 \mathrm{~g}$ cells $/ \mathrm{m}^{3}$. The oxygen concentration $0.5 \mathrm{mg} / \mathrm{l}$ corresponds to the aerobic-anaerobic interface. 


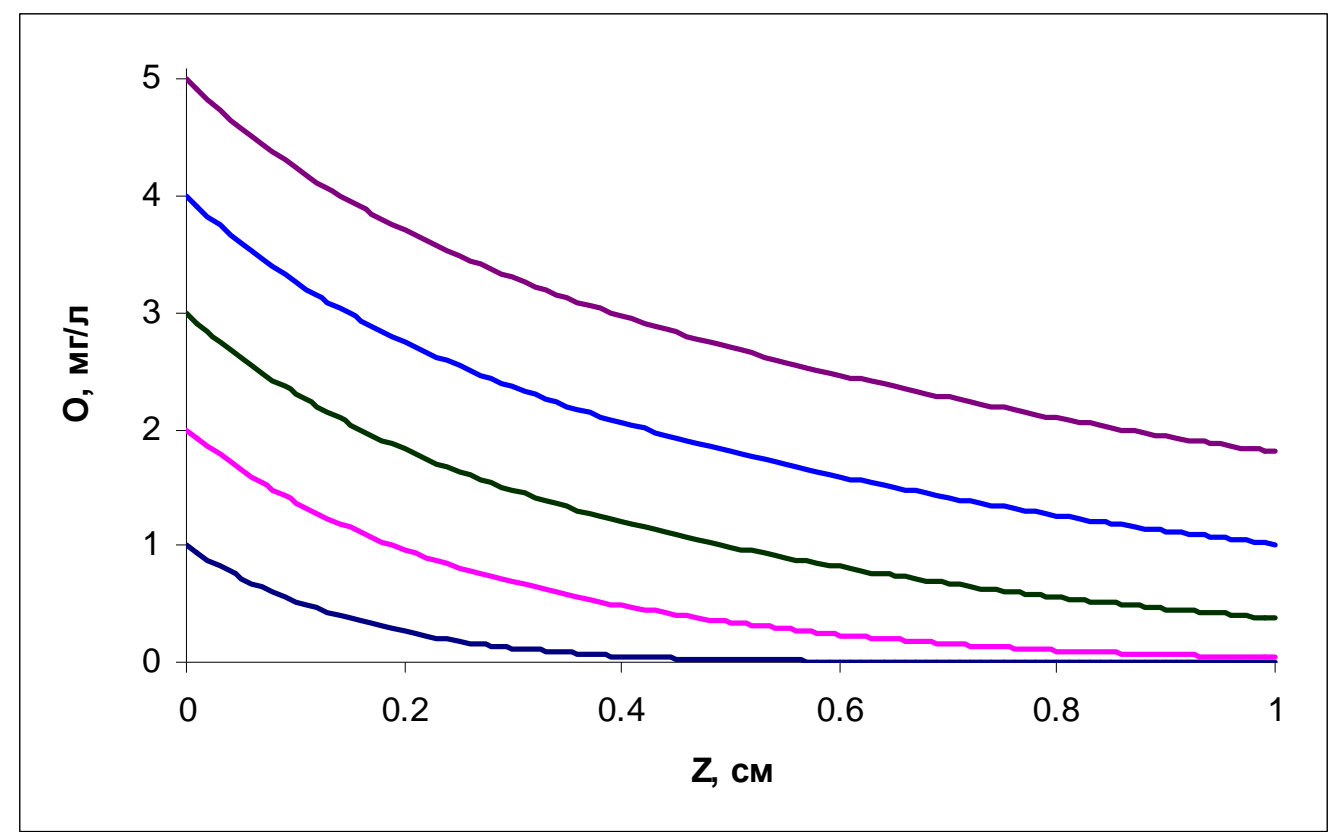

Fig. 5. Depth profiles of oxygen for System D at different oxygen concentrations in the overlying water.

The obtained dependence $J$ vs. $O_{0}$ contains 9 initial model parameters $R, Y, V, S_{0}, K_{S}, K_{O}, D$, $\mu_{m}, k_{c}$ (see Table 1). After grouping, the number of parameters is reduced to four: $J_{p}, s_{0}, \kappa, K_{O}$, see (16). Finally, in the special cases the following three parameters persist: $J_{p}, s_{0}, K_{O}$ at $\lambda=0$ and $J_{p}, \kappa$, $K_{O}$ at $\lambda>>1$. The parameter $J_{p}$ can be determined separately using a set of experimental data corresponding to the oxygen consumption rate plateau. As a result, only two parameters persist ( $s_{0}$ and $K_{O}$ or $\kappa$ and $K_{O}$ ), which are determined by solving the reciprocal problem (Appendix 3).

The first equation in (16) leads to a simple way of estimating $J_{p}$ on the basis of empirical data. Actually, the product $R Y S_{0}$ is the well-known biological oxygen demand (BOD) expressed in mg O per liter of natural sediments. Hence, it is sufficient to measure the BOD and the sediment growth rate $V$ and then to multiply these quantities: $J_{p}=\mathrm{BOD} \times V$.

\section{CONCLUSIONS}

1. The model of aerobic biodegradation in benthic sediments developed here includes the balance equations for microbial mass, organic matter, and oxygen, written in a steady-state mode. Degradable organic matter is described as a single substrate and the microbial community as a single population. The substrate is present mainly in a particulate form settled from the water column. Substrate particles and microbial cells are immobilized by the sediment solid matrix. Oxygen penetrates into the sediment by diffusion. The oxygen and substrate at the water-sediment interface are 
maintained at constant concentrations. A simple Malthusian trophic function is unacceptable for this system because it does not support equilibria in populations. Therefore, we have used a more complex, logistic trophic function (known in theoretical ecology), which can support equilibria due to involving the competition effect. Analysis of the literature indicates that this model has not been applied earlier to benthic sediments. The model predicts the degradation rate versus the substrate content $S$ in the form $d S / d t \propto S^{2} /\left(S+K_{S}\right)^{2}$ implying two extreme cases: $d S / d t$ is invariant of $S$ at small $K_{S}$ and $d S / d t \propto S^{2}$ at large $K_{S}$, while the chemical models suppose $d S / d t \propto S$. This difference is important for modeling benthic sediments.

2. The model allowed us to express the oxygen consumption rate $J$ through the oxygen concentration $O_{0}$ in the overlying water. The expression contains four generalized process parameters, while there are nine initial model parameters. There are two important special cases - labile and refractory organics - for which the number of parameters reduces to three. In the first case, the biomass specific growth rate $\mu$ is proportional to the substrate content $S$ and in the second one $\mu$ is independent of $S$ (the same is true for the biomass $B$ ). Thus, to completely reconstruct the oxygen consumption for any oxygen concentration it is now sufficient to determine only the three parameters for the sediment.

3. The dependence $J$ vs. $O_{0}$ has been calibrated for the three experimental systems of the literature, one of which has a low oxygen consumption rate and the other two high rate. The first system proves to be fitted better by supposing $\mu \propto S$, whereas for the other two there is no appreciable difference between the cases that $\mu$ is invariant of $S$ and $\mu \propto S$. To discriminate between the cases, additional information is needed, for example, about the dependence $B$ vs. $S$ bearing in mind that the model gives $B$ is invariant of $S$ for the first case and $B \propto S$ for the second. Some empirical data suggest the second dependence, though this suggestion is not strong. Taking $B \propto S$, we estimated the parameters of the trophic function for the system with low oxygen consumption. An attempt to apply a similar estimate to the two systems with high oxygen consumption was unsuccessful in view of their unsteadiness. The calculation of organic matter decay times indicates that the case $\mu$, $B=$ invar $S$ is characterized by longer times compared to the case $\mu, B \propto S$. Hence, the latter corresponds to labile organics, while the former to refractory. Actually, microbial cells metabolize labile organics quickly to reach high abundance, and in the environment they are found for a lack of substrate that limits the biomass growth rate and yields $B \propto S$. For refractory organic matter, metabolism is slow, the microbial abundance is small, and the biomass growth rate (and $B$ ) is independent of $S$.

4. The initial model parameters were determined for one of the three experimental systems (for reservoir benthic sediments) in agreement with the evidence of the literature. Depth profiles for 
oxygen, substrate, and biomass were computed. The thickness of the aerobic zone increases with oxygen concentration, especially when the latter passes to the plateau region of the curve $J\left(O_{0}\right)$.

5. The estimates of organic matter decay times, the microbial competition constant and the biomass growth rate, obtained for two continuous-flow systems and one batch system, showed that the continuous-flow experimental technique is not suitable for studying limnetic benthic sediments because the continuous-flow systems are unsteady. The batch system technique with short exposure of assays is preferable for this purpose.

\section{APPENDIX 1. NORMALIZATION}

Let us introduce the dimensionless variables $z, o, s, b, j$ instead of the initial ones $Z, O, S, B, J$ using the relations:

$$
Z=Z_{*} Z, \quad O=K_{O} O, \quad S=S_{*} S, \quad B=B_{*} b, \quad J=J_{*} j .
$$

Here the scale for $O$ has been chosen in advance, while the scales for the other quantities (marked by '*') can be found by substituting (A1) in (8)-(12) with regard to expression (3) and minimizing the number of parameters in the resulting equations. This procedure yields the relations

$$
\mu_{m}=k_{c} B_{*}, \quad \frac{V S_{*}}{Z_{*}}=\frac{\mu_{m} B_{*}}{Y}, \quad \frac{D K_{O}}{Z_{*}^{2}}=R \mu_{m} B_{*}, \quad J_{*}=\frac{D K_{O}}{Z_{*}},
$$

which allow the scales to be expressed as

$$
B_{*}=\frac{\mu_{m}}{k_{c}}, \quad Z_{*}=\frac{1}{\mu_{m}} \sqrt{\frac{D K_{O} k_{c}}{R}}, \quad S_{*}=\frac{\mu_{m}}{Y V} \sqrt{\frac{D K_{O}}{R k_{c}}}, \quad J_{*}=\mu_{m} \sqrt{\frac{D K_{O} R}{k_{c}}} .
$$

Using transformations (A1)-(A2), system (8)-(12) can be reduced to the dimensionless form

$$
\begin{gathered}
b=\frac{o s}{(o+1)(s+\kappa)}, \quad \frac{d s}{d z}=-b^{2}, \quad \frac{d^{2} o}{d z^{2}}=b^{2}, \\
s(0)=s_{0}, \quad o(0)=o_{0}, \quad o(\infty)=\frac{d o}{d z}(\infty)=0, \\
j=-\frac{d o}{d z}(0),
\end{gathered}
$$

where we have introduced the three dimensionless groupings:

$$
\kappa=\frac{K_{S}}{S_{*}}, \quad S_{0}=\frac{S_{0}}{S_{*}}, \quad O_{0}=\frac{O_{0}}{K_{O}} .
$$




\section{APPENDIX 2. SOLUTION OF THE PROBLEM}

The normalized problem (A3)-(A5) is solved as follows.

It is seen from (A3) that

$$
\frac{d^{2} o}{d z^{2}}=-\frac{d s}{d z}
$$

Integration of this equation in accordance with the boundary conditions (A4) and relation (A5) yields

$$
\frac{d o}{d z}=-j+s_{0}-s
$$

In addition, the second equation in (A3) implies

$$
\frac{d s}{d z}=-\left[\frac{o s}{(o+1)(s+\kappa)}\right]^{2} .
$$

Excluding $z$ from (A7) and (A8) gives

$$
\frac{d s}{d o}=\frac{1}{s-s_{0}+j}\left[\frac{o s}{(o+1)(s+\kappa)}\right]^{2}
$$

where the variables $s$ and $o$ can be separated:

$$
\left(s-s_{0}+j\right)\left(\frac{s+\kappa}{s}\right)^{2} d s=\left(\frac{o}{o+1}\right)^{2} d o .
$$

Integration of (A10) yields the following relation between $s$ and $o$ :

$$
\begin{aligned}
& \frac{1}{2}\left(s^{2}-s_{0}^{2}\right)+\left(2 \kappa-s_{0}+j\right)\left(s-s_{0}\right)+\kappa\left(\kappa-2 s_{0}+2 j\right) \ln \frac{s}{s_{0}}+\kappa^{2}\left(j-s_{0}\right)\left(\frac{1}{s_{0}}-\frac{1}{s}\right) \\
& =o-o_{0}-2 \ln \frac{o+1}{o_{0}+1}-\frac{1}{o+1}+\frac{1}{o_{0}+1} .
\end{aligned}
$$

The parameter $j$ in (A11) is still unknown. To determine it, we should analyze the behavior of the solution of (A11) as $z \rightarrow \infty$. It is clear that oxygen concentration and oxygen flux must tend to zero: $o \rightarrow 0, \quad d o / d z \rightarrow 0$. However, the substrate does not vanish completely in the deeper sediments, but is present at a finite concentration $s_{\infty}$, i.e. $s \rightarrow s_{\infty}$. As $z \rightarrow \infty$, (A7) implies $j=s_{0}-s_{\infty}$, or

$$
s_{\infty}=s_{0}-j .
$$

As $z \rightarrow \infty$, it is necessary to put $s=s_{\infty}$ and $o=0$ in (A11). After a series of transformations with regard to (A12), we come to the equation for $j$ :

$$
\frac{1}{2} j^{2}+\kappa\left(2-\frac{\kappa}{s_{0}}\right) j+\kappa\left(2 j-2 s_{0}+\kappa\right) \ln \frac{s_{0}}{s_{0}-j}=o_{0}-2 \ln \left(o_{0}+1\right)+1-\frac{1}{o_{0}+1} \equiv q\left(o_{0}\right),
$$


which implicitly determines $j$ as a function of three parameters: $\kappa, s_{0}$, and $o_{0}$.

The number of parameters in (A13) can be reduced to two by defining a new variable $x$ (instead of $j$ ) and two new parameters $\lambda$ and $v$ as follows:

$$
j=s_{0} x, \quad \lambda=\frac{\kappa}{s_{0}}, \quad v=\frac{2 q\left(o_{0}\right)}{s_{0}^{2}} .
$$

Substituting (A14) in (A13) and rearranging, we get:

$$
x^{2}+2 \lambda(2-\lambda) x-[4 \lambda x-2 \lambda(2-\lambda)] \ln (1-x)=v .
$$

This transcendental equation implicitly defines $x$ as a function of two arguments:

$$
x=f(\lambda, v) .
$$

For $\lambda>>1$, equation (A15) takes the asymptotic form:

$$
x+\ln (1-x) \approx-\frac{v}{2 \lambda^{2}}
$$

Its solution can be represented as a function of a single argument:

$$
x \approx f_{1}\left(\frac{v}{2 \lambda^{2}}\right)
$$

Combining (A18) and (A14), we find:

$$
x \approx f_{1}\left(\kappa^{-2} q\left(o_{0}\right)\right) \quad(\lambda>>1) .
$$

For $\lambda \rightarrow 0$, (A15) yields

$$
x \approx \sqrt{v} \text { at } v<1 ; \quad x=1 \text { at } v \geq 1
$$

or, recalling the definition of $v$ (A14),

$$
x \approx \min \left\{1, s_{0}^{-1} \sqrt{2 q\left(o_{0}\right)}\right\} \quad(\lambda<<1) .
$$

Formulas (A19) and (A21) describe the two extreme cases studied in the main text of the paper.

Oxygen and substrate depth profiles can be found using equation (A7), the boundary condition (A4) for oxygen, relation (A11) between $s$ and $o$, and equation (A13) for the flux $j$. This problem was solved numerically using the 4th-order Runge-Kutta method for (A7) [Ralston and Wilf, 1966] and Mueller's iteration method for (A11) and (A13) [Kristiansen, 1963]. The biomass depth profile can be found from the first equation of (A3).

\section{APPENDIX 3. THE MODEL CALIBRATION PROCEDURE}

Suppose that the dependence $J$ vs. $O_{0}$ is known for the sediment. Let the plateau value $J_{p}$ of the flux be already determined. Then instead of $J$, the ratio $J / J_{p}=x$ can be used as an observed quantity. Equation (A15) defines the theoretical dependence $x=f(\lambda, v)$. Because the parameter $v$ de- 
pends on the experimentally determined oxygen concentration, it must be expressed through $O_{0}$ using (A14) and changing $o_{0}$ in $O_{0} / K_{O}$. To calibrate the model, we use the least-squares method requiring the minimization of

$$
\sigma_{x}^{2}=\frac{1}{N-1} \sum_{i=1}^{N}\left\{x_{i}-f\left(\lambda, 2 s_{0}^{-2} q\left(K_{O}^{-1} O_{0 i}\right)\right\}^{2} \rightarrow \min _{\lambda, s_{0}, K_{O}}\right.
$$

by varying the three control parameters: $\lambda, s_{0}$ and $K_{O}$; where $\left\{x_{i}, O_{0 i} ; i=\overline{1, N}\right\}$ is the set of $N$ experimental points.

This problem determines the optimum control parameters corresponding to the global minimum of $\sigma_{x}$. Since this is an ill-posed problem, it imposes tough constraints on the accuracy of the empirical data. When the accuracy is insufficient, it is difficult to discern the global minimum among several local minima having close magnitudes but markedly distinguished values of the control parameters. The demands on the data accuracy can be abated by diminishing the number of control parameters. For example, in (A22) we may use one of the approximations (19) or (A21) instead of the exact dependence (A16), reducing the number of control parameters to two: $\kappa$ and $K_{O}$ for (A19) or $s_{0}$ and $K_{O}$ for (A21).

\section{ACKNOWLEDGMENTS}

This work was supported by Russian Foundation for Basic Research, project 96-05-66179.

\section{REFERENCES}

Alvarez, P.J.J., P.J. Anid, and T.M. Vogel, Kinetics of aerobic biodegradation of benzene and toluene in sandy aquifer material, Biodegradation, 2, 43-51, 1991.

Archer, D., S. Emerson, and C.E. Reimers, Dissolution of calcite in deep-sea sediments: $\mathrm{pH}$ and $\mathrm{O}_{2}$ microelectrode results, Geochim. Cosmochim. Acta, 53, 2831-2845, 1989.

Belanger, T.V., Benthic oxygen demand in Lake Apopka, Florida, Wat. Res., 15(2), 267-274, 1981.

Borden, R.C., and P.B. Bedient, Transport of dissolved hydrocarbons influenced by oxygen-limited biodegradation, 1, Theoretical development, Wat. Resour. Res., 22(13), 1973-1982, 1986.

Boudreau, B.P., A steady-state diagenetic model for dissolved carbonate species and $\mathrm{pH}$ in the porewaters of oxic and suboxic sediments, Geochim. Cosmochim. Acta, 51, 1985-1996, 1987. 
Boudreau, B.P., Modelling the sulfide-oxygen reaction and associated $\mathrm{pH}$ gradients in porewaters, Geochim. Cosmochim. Acta, 55, 145-159, 1991.

Brekhovskikh, V.F., Hydrophysical Factors of the Oxygen Regime Formation in Aquatic Environments, Nauka, Moscow, 1988.

Brekhovskikh, V.F., G.N. Vishnevskaya, L.S. Vlasova, M.A. Mordasov, and V.V. Romanov, The influence of macrobenthos organisms on mass transfer in benthic sediments, Wat. Resour., 17(1), 128-133, 1990.

Button, D.K., Kinetics of nutrient-limited transport and microbial growth, Microbiol. Rev., 49(3), 270-297, 1985.

Cai, W.-J., C.E. Reimers, and T. Shaw, Microelectrode studies of organic carbon degradation and calcite dissolution at a California continental rise site, Geochim. Cosmochim. Acta, 59, 497511, 1995.

Characklis, W.G., and K.C. Marshall, Biofilms: A basis for an interdisciplinary approach, in Biofilms, edited by W.G. Characklis and K.C. Marshall, pp. 341-394, Wiley, New York, 1990.

Chen, Y.-M., L.M. Abriola, P.J.J. Alvarez, P.J. Anid, and T.M. Vogel, Modeling transport and biodegradation of benzene and toluene in sandy aquifer material: Comparison with experimental measurements, Wat. Resour. Res., 28(7), 1833-1847, 1992.

Cunningham, A., and R.M. Nisbet, Transient and oscillations in continuous culture, in Mathematics in Microbiology, edited by M. Bazin, pp. 77-104, Academic Press, London, 1983.

Drabkova, V.G., Zonal Variation of Rates of Microbiological Processes in Lakes, Nauka, Leningrad, 1981.

Dzyuban, A.N., Determination of organic matter destruction in aquatic benthic sediments, Gidrobiol. Zh., 23(2), 30-35, 1987.

Edwards, R.W., and H. Rolley, Oxygen consumption of river muds, J. Ecol., 53, 1-19, 1965.

Emerson, S., Organic carbon preservation in marine sediments, in The carbon cycle and atmospheric $\mathrm{CO}_{2}$ : Natural variations Archean to present, edited by E.T. Sundquist and W.S. Broecker, pp. 78-87, AGU, 1985.

Emerson, S., and M.L. Bender, Carbon fluxes at the sediment-water interface of the deep sea: calcium carbonate preservation, J. Mar. Res., 39, 139-162, 1981.

Essaid, H.I., B.A. Bekins, E.M. Godsy, E. Warren, M.J. Baedecker, and I.M. Cozzarelli, Simulation of aerobic and anaerobic biodegradation processes at a crude oil spill site, Wat. Resour. Res., 31(12), 3309-3327, 1995.

Fillos, J., and A.H. Molof, Effect of benthal deposits on oxygen and nutrient economy of flowing waters, J. Wat. Pollut. Contr. Fed., 44(4), 644-662, 1972. 
Fuhrman, J.A., and R.T. Noble, Viruses and protists cause similar bacterial mortality in coastal seawater, Limnol. Oceanogr., 40(7), 1236-1242, 1995.

Graneli, W., The influence of Chironomus plumosus larvae on the oxygen uptake of sediment, Archiv für Hydrobiologie, 87(4), 385-403, 1979.

Hargrave, B.T., and G.A. Phillips, Decay times of organic carbon in sedimented detritus in a macrotidal estuary, Mar. Ecol. Prog. Ser., 56, 271-279, 1989.

Harvey, R.W., R.L. Smith, and L. George, Effect of organic contamination upon microbial distributions and heterotrophic uptake in Cape Cod, Mass. Aquifer, Appl. Environ. Microbiol., 48, 1197-1202, 1984.

Howell, J.A., Mathematical models in microbiology: Mathematical tool-kit, in Mathematics in Microbiology, edited by M. Bazin, pp. 37-76, Academic, San Diego, Calif., 1983.

Jeppesen, E., Diurnal variation in the oxygen uptake of river sediments in vitro by use of continuous flow-through systems, Hydrobiologia, 91, 189-195, 1982.

Kerner, M., and H. Gramm, Changes in oxygen consumption at the sediment-water interface formed by settling seston from Elbe estuary, Limnol. Oceanogr., 40(3), 544-555, 1995.

Khailov, K.M., Ecological Metabolism in Sea, Kiev, 1971.

Kindred, J.S., and M.A. Celia, Contaminant transport and biodegradation, 2, Conceptual model and test simulations, Wat. Resour. Res., 25(6), 1149-1159, 1989.

Kono, T., Kinetics of microbial cell growth, Biotechnol. Bioeng., 10, 105-131, 1968.

Kristiansen, G.K., Zero of arbitrary function, Bit, 3, 205-206, 1963.

Kuznetsov, S.I., Limnetic Microflora and Its Geochemical Activity, Leningrad, 1970.

MacQuarrie, K.T.B., E.A. Sudicky, and E.O. Frind, Simulation of biodegradable organic contaminants in groundwater, 1, Numerical formulation in principle directions, Wat. Resour. Res., 26(2), 207-222, 1990.

Middelburg, J.J., A simple rate model for organic matter decomposition in marine sediments, Geochim. Cosmochim. Acta, 53, 1577-1581, 1989.

Mizandrontsev, I.B., Chemical Processes in Benthic Sediments, Nauka, Novosibirsk, 1990.

Molz, F.J., M.A. Widdowson, and L.D. Benefield, Simulation of microbial growth dynamics coupled by nutrient and oxygen transport in porous media, Wat. Resour. Res., 22(8), 1207-1216, 1986.

Molz, F.J., and M.A. Widdowson, Internal inconsistencies in dispersion-dominated models that incorporate chemical and microbial kinetics, Wat. Resour. Res., 24(4), 615-619, 1988.

Newell, R.C, M.I. Lucas, and E.A.S. Linley, Rate of degradation and efficiency of conversion of phytoplankton debris by marine microorganisms, Mar. Ecol. Prog. Ser., 6, 123-136, 1981. 
Park, S.S., and P.R. Jaffe, Development of a sediment redox potential model for assessment of postdepositional metal mobility, Ecol. Modelling, 91(1-3), 169-181, 1996.

Pavlyutin, A.P., and A.P. Ostapenya, Destruction of detritus organic matter, in Theory and Practice of Biological Self-Purification of Polluted Waters, pp. 207-210, Moscow, 1972.

Rabouille, C., and J.-F. Gaillard, A coupled model representing deep sea organic carbon mineralization and oxygen consumption in surficial sediments, J. Geophys. Res., 96, 2761-2776, 1991.

Ralston, A., and H.S. Wilf, Mathematical Methods for Digital Computers, Wiley, New York, 1966.

Starink, M., M.-J. Bar-Gilissen, R.P.M. Bak, and T.E. Cappenberg, Seasonal and spatial variations in heterotrophic nanoflagellate and bacteria abundances in sediment of a freshwater littoral zone, Limnol. Oceanogr., 41(2), 234-242, 1996.

Stouthamer, A.H., Theoretical calculations on the influence of the inorganic nitrogen source on parameters for aerobic growth of microorganisms, Antonie van Leeuwenhoek, 43, 351-367, 1977.

Svirezhev, Yu.M., Nonlinear Waves, Dissipative Structures, and Catastrophes in Ecology, Nauka, Moscow, 1987.

Thomas, J.M., M.D. Lee, and C.H. Ward, Microbial numbers and activity in the subsurface at a creosote waste site (abstract), paper presented at Proceedings, American Society of Microbiology, Las Vegas, NV, 1985.

Truex, M.J., F.J. Brockman, D.L. Johnstone, and J.K. Fredrickson, Effect of starvation on induction of quinoline degradation for a subsurface bacterium in a continuous-flow column, Appl. Environ. Microbiol., 58, 2386-2392, 1992.

Widdowson, M.A., Comment on “An evaluation of mathematical models of the transport of biologically reacting solutes in saturated soils and aquifers” by P. Baveye and A. Valocchi, Wat. Resour. Res., 27(6), 1375-1378, 1991.

Wood B.D., and C.N. Dawson, Effects of lag and maximum growth contaminant transport and biodegradation modeling, in Mathematical Modeling in Water Resources, vol. 2, edited by T.F. Russell et al., pp. 317-324, Elsevier Applied Science, New York, 1992.

Wood, B.D., C.N. Dawson, J.E. Szecsody, and G.P. Streile, Modeling contaminant transport and biodegradation in a layered porous media system, Wat. Resour. Res., 30(6), 1833-1845, 1994.

Zysset, A., F. Stauffer, and T. Dracos, Modeling of reactive groundwater transport governed by biodegradation, Wat. Resour. Res., 30(8), 2423-2434, 1994. 